\title{
Thrombin generation in low plasma volumes
}

Saartje Bloemen ${ }^{1,2^{*}}$ (D) Hilde Kelchtermans ${ }^{1,2}$ and H. Coenraad Hemker ${ }^{1,2}$ Abstract: Accurate thrombin generation determination by calibrated automated thrombinography can be sustained
when reducing the plasma and reagent volumes up to half, but not for higher reductions or plasma dilutions.

Keywords: Thrombin generation, Calibrated automated thrombinography, Low volumes

Calibrated automated thrombinography (CAT) i.e. the measurement of the complete course of the thrombin concentration (thrombin generation, TG) in clotting blood(-plasma), is a global function test of the coagulation system. Whereas clotting assays measure only the initiation phase of TG, the full TG curve provides information on the propagation and decay phase as well and therefore also reflects the inhibitory factors (tissue factor pathway inhibitor, proteins $\mathrm{C}$ and $\mathrm{S}$ and antithrombin). Since sample volumes can be limited in case of e.g. preexisting sample sets or in pediatric studies, we attempted to minimize the volume of plasma necessary to obtain a TG curve with CAT and found that for volumes below $40 \mu \mathrm{l}$ of plasma (i.e. final volume of $60 \mu \mathrm{l}$ ) the experimental precision cannot be maintained.

Previous studies showed that the total amount of thrombin activity (endogenous thrombin potential, ETP) as represented by the area under the TG curve, as well as the peak thrombin activity have been shown to correlate significantly with the risk of bleeding as well as venous thrombosis [1-10]. A relation with arterial thrombosis does exist, but is less straightforward $[11,12]$. In TG measurements, adequate calibration requires compensation for substrate consumption and inner filter effect. Therefore, a calibrator must be run in parallel with the sample in which TG is measured, which doubles the amount of plasma required; moreover, the experiments are preferably executed in duplicate. Also, if maximal information on the TG system is to be obtained,

\footnotetext{
* Correspondence: s.bloemen@thrombin.com

${ }^{1}$ Synapse Research Institute, Cardiovascular Research Institute Maastricht, Maastricht University Medical Center, Maastricht, the Netherlands

${ }^{2}$ Department of Biochemistry, Cardiovascular Research Institute Maastricht,

Maastricht University Medical Center, Maastricht, the Netherlands
}

experiments in the presence of different concentrations of tissue factor (TF), with and without added thrombomodulin (TM) or activated protein $\mathrm{C}$ should be performed. Thus, although the volume necessary per CAT measurement $(<500 \mu \mathrm{l})$ is comparable to that of other clotting assays, it is a question of significant practical importance whether the volume of plasma required per test can be reduced.

Earlier results show that diminishing the plasma volume without decreasing the total volume, i.e. diluting the plasma further than 2:3, seriously impairs the sensitivity of the method to factors other than pro- and antithrombin [13]. We therefore opted for decreasing the volume of all reactants.

First, we evaluated different reductions of the final volume $(90 \mu \mathrm{l}, 60 \mu \mathrm{l}$ and $30 \mu \mathrm{l})$. At volumes $<1 / 2$ (i.e. $<$ $60 \mu \mathrm{l})$ of the original the experimental error increased significantly (data not shown), so we decided to further develop a method in which all volumes are halved, the 'MidiCAT'.

In a MidiCAT measurement, $10 \mu \mathrm{l}$ of trigger and $40 \mu \mathrm{l}$ of platelet poor plasma (PPP) are added in a well of a round-bottom 96-well plate (Immulon $2 \mathrm{HB}$ ) and after 5 min incubation the reaction is started by dispensing $10 \mu \mathrm{l}$ of substrate-recalcification mixture. The plasma ratio as well as the final concentrations are the same as in the CAT method, i.e. 5 pM TF (Innovin, Dade-Behring, Marburg, Germany), $4 \mu \mathrm{M}$ phospholipids (PL) (PS/PE/ PC 20/20/60\%, Avanti Polar Lipids Inc., Alabaster, AL, USA) in Hepes buffer containing $5 \mathrm{mg} / \mathrm{ml}$ bovine serum albumin in addition to $416.7 \mu \mathrm{M}$ Z-Gly-Gly-Arg-aminomethylcoumarin (Bachem) and $16.7 \mathrm{mM} \mathrm{CaCl}_{2}$ in Hepes buffer containing $60 \mathrm{mg} / \mathrm{ml}$ bovine serum albumin (FluCa). The same TF/PL solution was used for analysis of one set of samples with both measurement procedures. FluCa was freshly prepared for each run using the 
same batch of reagents for both procedures. For each set of samples both procedures were performed on the same day. Normal pooled plasma (NPP) was included in each run $(n=4)$. Forty-three samples were tested with both procedures. According to the Clinical and Laboratory Standards Institute (CLSI) guidelines for method procedure comparison when introducing a different measurement procedure, at least 40 patient samples should be measured that span the measuring interval of the assay. Samples were chosen to cover the range for the ETP and peak, since these are the most important variables in CAT. All healthy donors $(n=37)$ and patients $(n=6)$ provided informed consent and the study protocol was evaluated by the local medical ethical committee. Donors were considered healthy when they were not using any anticoagulant drugs and had no history of bleeding or thrombosis. Donors using oral contraceptives with known high ETP and peak values were chosen
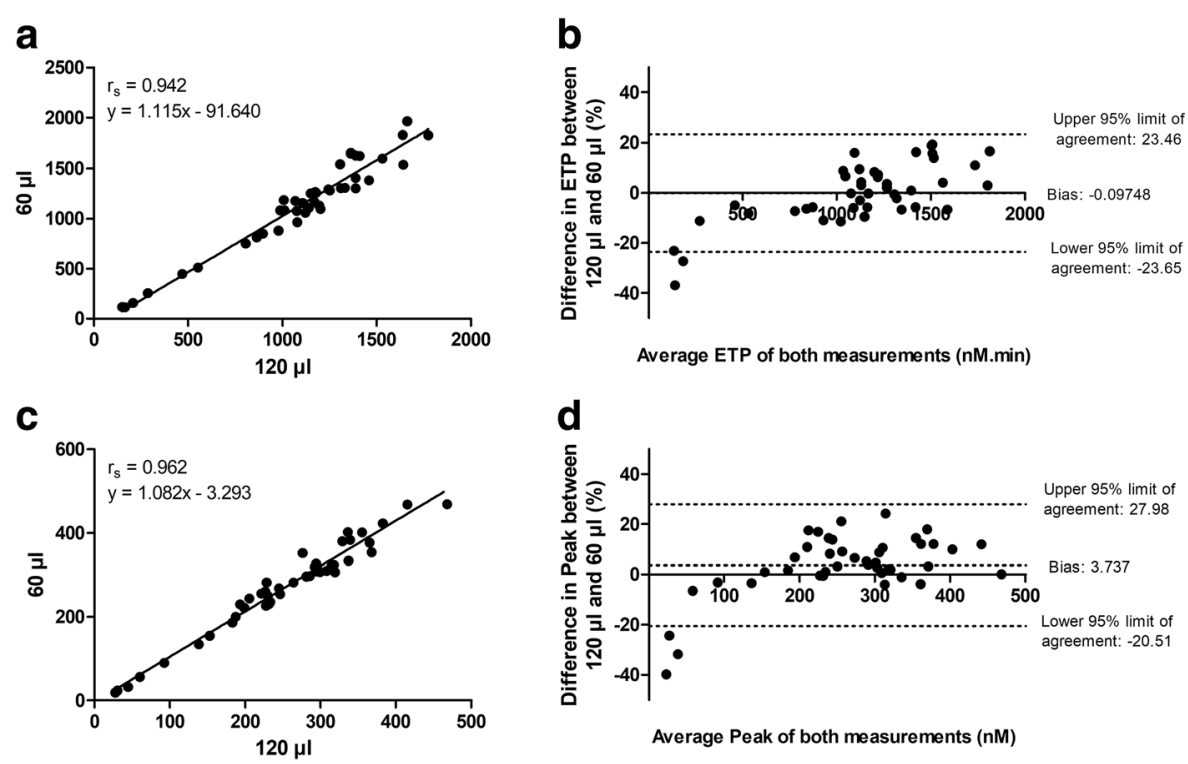

Average ETP of both measurements (nM.min)

d

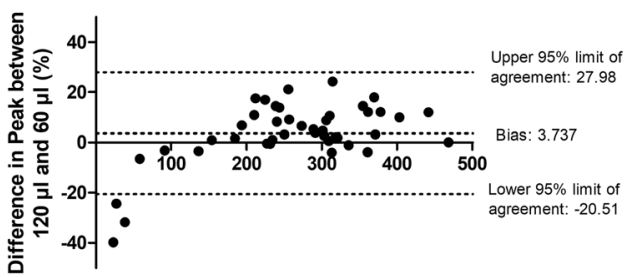

Average Peak of both measurements (nM)

e

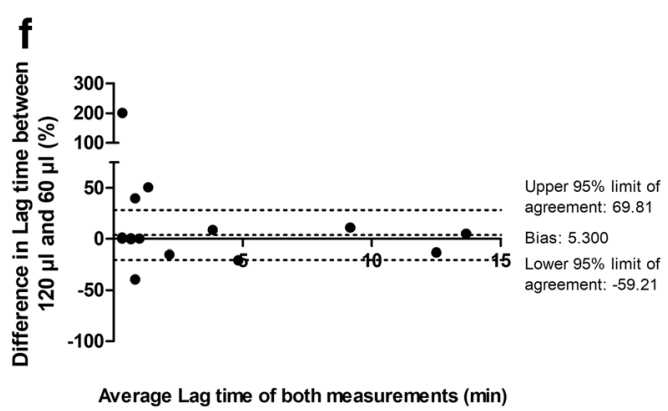

g
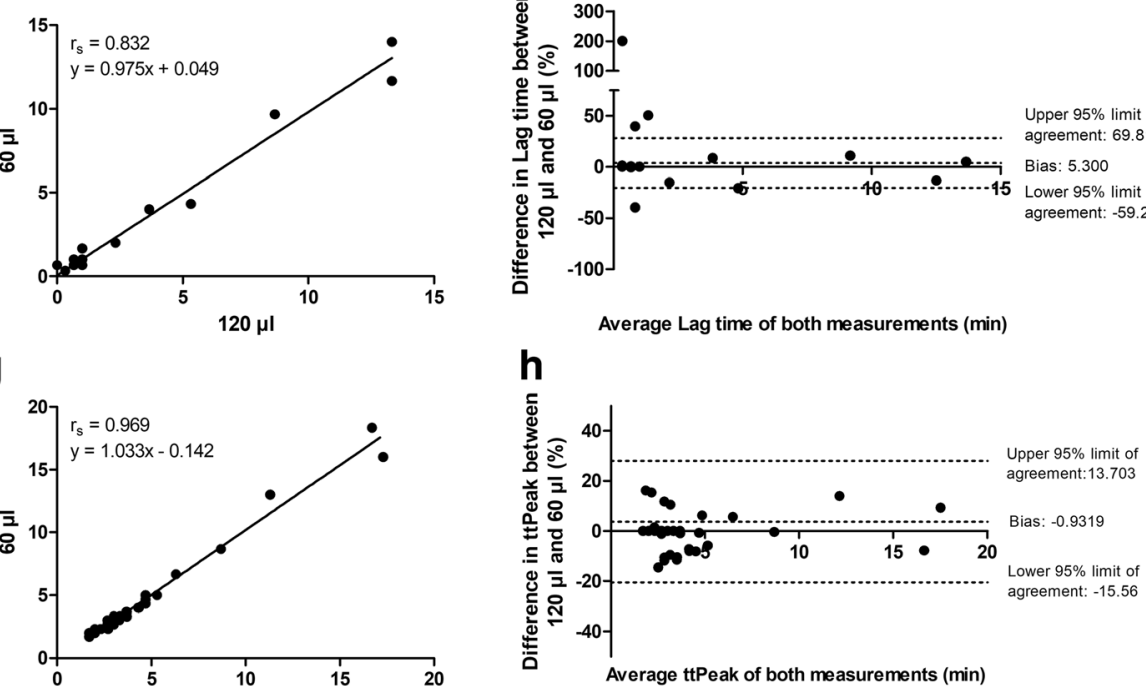

Fig. 1 Correlation and Bland-Altman plots of thrombin generation parameters in MidiCAT and regular CAT. The correlation between the MidiCAT (60 $\mu \mathrm{l}$ final volume) and the regular CAT (120 $\mu$ l final volume) was determined for the four main CAT parameters i.e. a endogenous thrombin potential (ETP), (c) peak, (e) lag time and (g) time-to-peak (ttPeak) in 43 healthy donors using 5 pM tissue factor (measured in duplicate). The Spearman correlation coefficient is indicated. Bland-Altman plots were constructed analyzing the percentage difference of the two methods (100*(A-B)/average) versus the average ((A+B)/ 2) of the two methods. Method A was the MidiCAT and method B was the regular CAT. Plots were prepared for (b) ETP, (d) peak, (f) lag time and (h) ttPeak. For all analyses 43 subjects were measured. Of note, for the lag time and time-to-peak several subjects had the same result, because of which it seems that less dots are depicted in the graphs 
to cover the higher range of values. Patients using vitamin $\mathrm{K}$ antagonists were included to provide samples in the lower range of the ETP and peak values. Plasmas from two healthy donors and two different NPP were also analyzed in the absence of TF, using both measurement procedures, to evaluate the level of contact activation.

Spearman correlation coefficients were defined to assess the correlation between the two methods. BlandAltman plots were constructed to evaluate the differences and bias in results between the two procedures. Here the percentage difference of the two methods $(100 *(\mathrm{~A}-\mathrm{B}) /$ average $)$ versus the average $((\mathrm{A}+\mathrm{B}) / 2)$ of the two methods was analyzed (method A: MidiCAT, method B: regular CAT). Passing-Bablok regression was performed to analyze the comparability of the measurements. Analyses were performed using GraphPad Prism (version 5.00) or MedCalc (version 17.7.2).

We compared TG in PPP of 43 healthy donors using the original CAT and our MidiCAT tested in duplicate. The correlation between the two techniques was very good for all parameters (Fig. 1, left panels; Spearman correlation coefficients for all parameters above 0.940, apart from lag time: $r_{s}=0.832$ ). The intra-assay variation for the new assay ranged between 0.5 and $2.0 \%$ for the four TG parameters. The inter-assay CV was for lag time: $11.0 \%$, ETP: $6.5 \%$, peak: $4.7 \%$ and time-to-peak: $5.4 \%$ for the regular CAT (determined in NPP in 37 runs) and respectively $8.6 \%, 3.6 \%, 3.1 \%$ and $5.4 \%$ for the MidiCAT (determined in NPP in 34 runs). The medians and interquartile ranges are shown in Table 1 . The bias as deducted from the Bland-Altman curves was between $-0.93 \%$ and $5.3 \%$ (Fig. 1, right panels). At lower ETP and peak levels the regular CAT resulted in higher values and at higher ETP and peak levels the MidiCAT resulted in higher values. For the time-dependent parameters the distribution was more even. Passing-Bablok regression equations were for ETP y $=1.14$ (95\% CI: 1.05 to 1.27$) \mathrm{x}-124.086$ (95\% CI: -260.51 to -45.05$)$, for peak $\mathrm{y}=1.09$ (95\% CI: 1.03 to 1.17$) \mathrm{x}-9.231$ (95\% CI: -22.61 to 2.36), for lag time $y=1.00$ (95\% CI: 0.99 to 1.01$) x+$

Table 1 Median and interquartile ranges of MidiCAT $(60 \mu \mathrm{l})$ and regular CAT $(120 \mu \mathrm{l})$ in 43 subjects

\begin{tabular}{cllll}
\hline & & $25 \%$ Percentile & Median & $75 \%$ Percentile \\
\hline Lag time (min) & $120 \mu \mathrm{l}$ & 0.67 & 0.67 & 1.00 \\
& $60 \mu \mathrm{l}$ & 0.67 & 0.67 & 1.00 \\
ETP (nM.min) & $120 \mu \mathrm{l}$ & 988.8 & 1169.0 & 1362.0 \\
& $60 \mu \mathrm{l}$ & 962.0 & 1174.0 & 1401.0 \\
Peak (nM) & $120 \mu \mathrm{l}$ & 198.7 & 264.1 & 319.4 \\
& $60 \mu \mathrm{l}$ & 226.7 & 282.5 & 333.6 \\
Time-to-peak (min) & $120 \mu \mathrm{l}$ & 2.67 & 3.00 & 4.30 \\
& $60 \mu \mathrm{l}$ & 2.67 & 3.00 & 4.00 \\
\hline
\end{tabular}

0.00 (95\% CI: -0.01 to 0.01 ) and for time-to-peak $\mathrm{y}=$ $0.99(95 \% \mathrm{CI}: 0.92$ to 1.00$) \mathrm{x}+0.011$ (95\% CI: 0.00 to 0.22 ). These equations indicate similarity between the two procedures for all four parameters. Additionally, the level of contact activation between the two measurement procedures was estimated (at $0 \mathrm{pM}$ TF and $4 \mu \mathrm{M} \mathrm{PL}$ ), providing similar results (data not shown).

We conclude that accurate measurement of TG curves is feasible in half the volume of the original method, but not less. Since there is a higher surface-to-volume ratio, it could be postulated that there may potentially be a higher level of contact activation in the MidiCAT. However, we found similar results between both procedures. Looking at the Bland-Altman curves, the bias was higher at the lower end of the measurement range. Our measurements were performed with in-house reagents using $5 \mathrm{pM}$ as a final TF concentration, which are comparable to the commercially available reagents for CAT (Stago PPPReagent $t^{\oplus}$ ). However, for other TF concentrations the differences are not yet known. Additionally, although similar results are obtained with both measurement procedures, we recommend using one procedure within one study.

\section{Abbreviations}

CAT: calibrated automated thrombinography; CLSI: Clinical and Laboratory Standards Institute; ETP: endogenous thrombin potential; NPP: normal pooled plasma; PL: phospholipids; PPP: platelet poor plasma; TF: tissue factor; TG: thrombin generation; TM: thrombomodulin

\section{Acknowledgements \\ The authors would like to thank Joke Konings for her contribution to the experiments.}

Funding

This research did not receive any external grant from funding agencies.

Availability of data and materials

The datasets used and/or analyzed during the current study are available from the corresponding author on reasonable request.

\section{Authors' contributions}

SB designed research, performed experiments, analyzed data and was a major contributor in writing the manuscript. HK performed experiments and reviewed the manuscript. $\mathrm{HCH}$ designed research and was a major contributor in writing the manuscript. All authors read and approved the final manuscript.

\section{Ethics approval and consent to participate}

Approval for inclusion of healthy donors was granted by the ethical committee medisch-ethische toetsingscommissie academisch ziekenhuis Maastricht/Universiteit Maastricht (METC azM/UM) (healthy donors: METC 123-069, patients: METC 11-4-142). We obtained written consent from all subjects.

Donors were recruited to donate blood for the purpose of technically validating thrombin generation techniques. The patients were included in a previous study [1] and provided consent to use the collected sample for additional research concerning thrombin generation testing. 


\section{Competing interests}

Bloemen $\mathrm{S}$ and Kelchtermans $\mathrm{H}$ are employed by Synapse Research Institute which is a research company part of Diagnostica Stago. Hemker HC is consultant for Synapse Research Institute and Diagnostica Stago.

\section{Publisher's Note}

Springer Nature remains neutral with regard to jurisdictional claims in published maps and institutional affiliations.

Received: 18 October 2017 Accepted: 19 February 2018

\section{Published online: 15 May 2018}

\section{References}

1. Bloemen S, Zwaveling S, Ten Cate H, Ten Cate-Hoek A, de Laat B. Prediction of bleeding risk in patients taking vitamin $\mathrm{K}$ antagonists using thrombin generation testing. PLoS One. 2017;12:e0176967.

2. Hemker HC, Al Dieri R, De Smedt E, Beguin S. Thrombin generation, a function test of the haemostatic-thrombotic system. Thromb Haemost. 2006;96:553-61.

3. Ten Cate H. Thrombin generation in clinical conditions. Thromb Res. 2012; 129:367-70.

4. Dargaud Y, Hoffman M, Lefrapper L, Lin FC, Genty A, Chatard B, et al. Bleeding risk in warfarinized patients with a therapeutic international normalized ratio: the effect of low factor IX levels. J Thromb Haemost. 2013; 11:1043-52.

5. Segers $\mathrm{O}$, van Oerle $\mathrm{R}$, ten Cate $\mathrm{H}$, Rosing J, Castoldi E. Thrombin generation as an intermediate phenotype for venous thrombosis. Thromb Haemost 2010;103:114-22.

6. Bosch Y, Al Dieri R, ten Cate H, Nelemans P, Bloemen S, Hemker C, et al. Preoperative thrombin generation is predictive for the risk of blood loss after cardiac surgery: a research article. J Cardiothorac Surg. 2013;8:154

7. Robert S, Ghiotto J, Pirotte B, David JL, Masereel B, Pochet L, et al. Is thrombin generation the new rapid, reliable and relevant pharmacological tool for the development of anticoagulant drugs? Pharmacol Res. 2009;59:160-6.

8. Dargaud Y, Trzeciak MC, Bordet JC, Ninet J, Negrier C. Use of calibrated automated thrombinography $+/$ - thrombomodulin to recognise the prothrombotic phenotype. Thromb Haemost. 2006;96:562-7.

9. Trossaert M, Regnault V, Sigaud M, Boisseau P, Fressinaud E, Lecompte T. Mild hemophilia a with factor VIII assay discrepancy: using thrombin generation assay to assess the bleeding phenotype. J Thromb Haemost. 2008;6:486-93.

10. Groeneveld D, Porte RJ, Lisman T. Thrombomodulin-modified thrombin generation testing detects a hypercoagulable state in patients with cirrhosis regardless of the exact experimental conditions. Thromb Res. 2014;134:753-6.

11. Ten Cate H, Hemker HC. Thrombin Generation and Atherothrombosis: What Does the Evidence Indicate? J Am Heart Assoc. 2016;5(8). https://doi.org/10. 1161/JAHA.116.003553.

12. Smid M, Dielis AW, Winkens M, Spronk HM, van Oerle R, Hamulyak K, et al. Thrombin generation in patients with a first acute myocardial infarction. J Thromb Haemost. 2011:9:450-6.

13. De Smedt E, Wagenvoord R, Hemker HC. The technique of measuring thrombin generation with fluorogenic substrates: 3 . The effects of sample dilution. Thromb Haemost. 2009:101:165-70.

\section{Submit your next manuscript to BioMed Central and we will help you at every step:}

- We accept pre-submission inquiries

- Our selector tool helps you to find the most relevant journal

- We provide round the clock customer support

- Convenient online submission

- Thorough peer review

- Inclusion in PubMed and all major indexing services

- Maximum visibility for your research

Submit your manuscript at www.biomedcentral.com/submit 